\title{
Emzirme Sürecinde Olan Annelerin Emzirme Davranışlarını Yönlendiren Tutumlarının İncelenmesi
}

\author{
Investigation of Mothers Attitudes During Breastfeeding Affecting Breastfeeding \\ Behavior
}

\section{Nurdan AKÇAY DİDIŞEN ${ }^{1 \text { A,B,D, }}{ }_{\odot}$, Hatice UZŞEN $^{1 \text { A,B,C,D,E,F,G }}{ }_{\odot}$,}

\author{
Emel BULDUR ${ }^{2}$ A,B,C,E \\ ${ }^{1}$ Ege Üniversitesi Hemşirelik Fakültesi Çocuk Sağlığı ve Hastalıkları Hemşireliği Bölümü, İzmir, Türkiye \\ ${ }^{2}$ Ege Üniversitesi Çocuk Hastanesi, İzmir, Türkiye
}

ÖZ

\begin{abstract}
Amaç: Emzirme sürecinde olan annelerin emzirme davranışlarını yönlendiren tutumlarının incelenmesi amacıyla uygulanmıştır.

Yöntem: Tanımlayıcı ve kesitsel olarak planlanan araştırma, Haziran 2017-Haziran 2018 tarihleri arasında bir üniversite hastanesinde gerçekleştirilmiştir. Gönüllü 307 anne ile tamamlanan çalışmada 'Birey Tanılama Formu' ve ‘Emzirme Tutumunu Değerlendirme Ölçeği’ kullanılmıştır. İstatistiksel olarak tanımlayıcı analizler yapılarak değişkenler arasında One Way Anova testi ve bağımsız gruplarda t testi kullanılmıştır.

Bulgular: Annelerin sosyo-demografik özellikleri doğrultusunda yaş ortalamasının $28 \pm 6$ olduğu, \%30,9 1 'u liseden mezun olup ve $\% 50,2 \pm 0,5$ 'sinin çalıştığı saptanmıştır. Annelerin \%72,3'ünün emzirme deneyimi olduğu, \%28,8'inin bebeğini 13-18 ay emzirdiği, \%28,4'ünün 19-24 ay emzirdiği belirlenmiştir. Annelerin \%75,6's1 emzirme eğitimi almıştır. Emzirme eğitimi alan annelerin bu eğitimi \%44.,6'sının sağlık personelinden, \%6,8'inin aile büyüklerinden aldıkları saptanmıştır. Çalışmada emzirme tutumu değerlendirme ölçeği toplam puan ortalamasının $85.73 \pm 18$ olduğu belirlenmiştir. Eğitim durumu ve emzirme süreleri ile ölçek toplam puanları arasında anlamlı bir fark saptanmıştır $(\mathrm{p}<0,05)$. Illkokul mezunu olan ve gebelik sayısı çok olan annelerin emzirme tutum puanının arttığı saptanmıştır.

Sonuç: Annelerin emzirme davranışlarını yönlendiren tutumlarının incelendiği çalışmada, emzirme eğitimini büyük oranda almış olmalarına rağmen emzirme tutumu değerlendirme ölçek puan ortalamaları düşüktür. Bu durumun örneklem grubunun az olmasından kaynaklanabileceği gibi emzirmeyi etkileyecek diğer biyolojik, psikolojik, sosyal, kültürel ve ekonomik etkenlerden kaynaklanabileceği düşünülmektedir. Annelerin ve anne adaylarının doğum öncesinden başlanarak emzirme davranış ve tutumlarının geliştirilmesi için gerekli eğitimler düzenlenmelidir.
\end{abstract}

Anahtar Kelimeler: Emzirme, Tutum, Anne, Emzirme Süreci.

ABSTRACT

Objective: It was applied to investigate the attitudes of the mothers in the breastfeeding process affecting their breastfeeding behaviors.

Method: The descriptive and cross-sectional study was conducted in a university hospital between June 2017 and June 2018. The study was completed with 307 mothers who volunteered to participate in the study. One way Anova test and independent $\mathrm{t}$ test were used among the variables.

Results: According to the socio-demographic characteristics of the mothers, the mean age was $28 \pm 6,30.9 \pm 1 \%$ were graduated from high school and $50.2 \pm 0.5 \%$ were working. It was determined that $72.3 \%$ of the mothers had breastfeeding experience, $28.8 \%$ had breastfed their baby for 13-18 months and $28.4 \%$ had breastfed for $19-24$ months. $75.6 \%$ of mothers received

Sorumlu Yazar: Hatice UZŞEN

Ege Üniversitesi Hemşirelik Fakültesi Çocuk Sağlığı ve Hastalıkları Hemşireliği Bölümü, İzmir/TÜRKIYE

hatice_uzsen35@hotmail.com

Geliș Tarihi: 26.11.2018 - Kabul Tarihi: 11.04.2020

* Çalışma, IV. International Multidisciplinary Congress Of Eurasia, Roma-İtalya, 23-24 Ağustos 2017 tarihinde sözel

bildiri olarak sunulmuștur.

Yazar Katkıları: A) Fikir/Kavram, B) Tasarım, C) Veri Toplama ve/veya İşleme, D) Analiz ve/veya Yorum, E) Literatür

Taraması, F) Makale Yazımı, G) Eleştirel İnceleme 
breastfeeding training. It was found that $44.6 \%$ of the mothers received breastfeeding training from health personnel and $6.8 \%$ from the family elders. Breastfeeding attitude assessment scale total score average was $85.73 \pm 18$. There was a significant difference between educational status, breastfeeding time and total scale scores $(\mathrm{p}<0.05)$.

Conclusion: In the study, although the breastfeeding education was largely received, the mean scores of the breastfeeding attitude assessment scale were low. It is thought that this situation may be due to the low sample size and other biological, psychological, social, cultural and economic factors that may affect the attidues of mothers' breastfeeding process. Breastfeeding trainings should be organized to developed breastfeeding behaviors and attitudes of mothers and expectant mothers starting before birth.

Key words: Breastfeding, Attidues, Mother, Breastfeding Duration.

\section{GİRiş}

Ulusal ve uluslararası sağlık örgütleri, annelerin yenidoğan bebekleri ilk 6 ay sadece anne sütüyle beslemelerini önermektedir. Büyüme ve gelişmenin optimum düzeyde gerçekleşebilmesi için annenin bebeğini kendi sütüyle beslemesi gerekmektedir (1-3). Yapılan çalışmalar incelendiğinde anne sütüyle beslenmenin sağlık, ekonomik ve psikolojik yönden birçok yararlarının olduğu bilinmektedir (4). Literatürde ayrıca anne sütünün bebeği birçok hastalıktan (pnömoni, tüberküloz, ishal, otitis media, kızamık vb.) koruduğu ve ani bebek ölüm riskini azalttığı vurgulanmaktadır (2-7). Düşük gelirli ve orta gelirli ülkelerde, yüksek gelirli ülkelere göre anne sütünün önemi daha iyi kavranmış olmakla birlikte annelerin daha uzun süre bebeklerini anne sütüyle besledikleri saptanmıştır (3,8-11). Ülkemizde ise emzirme davranışı oldukça yaygın olmakla birlikte hemen hemen bütün bebekler anneleri tarafindan emzirilmektedir (12). 2018 Türkiye Nüfus ve Sağlık Araştırması (TNSA) sonuçlarına göre ortalama emzirme süresinin 16,7 ay olduğu, ilk 6 ayda anne sütü ile beslenme oranının $\% 88$, yirmi dört ayda ise \%39 olduğu belirlenmiştir (13).

Birçok yararı olan emzirmenin başarılı bir şekilde sürdürülmesi önemli sağlık hedeflerinden biri olarak kabul edilmekte, emzirmenin korunmas1, özendirilmesi ve desteklenmesi gerekliliği her firsatta ifade edilmektedir (12). Ancak bugün anne sütünün önemi bilinmesine rağmen birçok ülkede etkili emzirmenin sağlanması ve sürdürülmesinde sorunlar yaşanmaktadır. Anne sütüyle besleme; annenin ve bebeğin sağlık durumu, çoğul bebeklerin varlığı, annenin çalışma durumu, ailenin ve toplumun tutum ve değerleri, emzirme sürecinde yaşanan zorluklar, kentleşme, beden imajının değişeceği düşüncesi vs. gibi birçok etmenden etkilenmektedir (14). Tüm bu süreçlerin içerisinde emzirme davranışını yönlendiren tutumlarının detaylı olarak belirlenmesi, sürecin kesintisiz bir şekilde devamının sağlanması, ortaya çıkabilecek akut durumlara yönelik uygun yaklaşımın verilmesi ile birlikte bebeğin beslenme yönetiminin de sorunsuz ve kesintisiz bir şekilde ilerlemesine katkı sağlayacaktır. Pediatri hemşiresinin doğumdan sonraki ilk zamanlarda annenin bebek ile etkileşimini sağlayan ve emme durumunu gözlemleyip destekleyen kişi olması, eğitici rolü ile anne sütünün önemi hakkında anneyi bilgilendirmesi, bebeğin ilk defa emzirilmesine danışmanlık edip emzirmenin sürdürülmesinde yer alması hemşirenin önemli rollerinden biridir.

$\mathrm{Bu}$ çalışma emzirme sürecinde olan annelerin emzirme davranışlarını yönlendiren tutumlarının incelenmesi amacıyla uygulanmıştır. 


\section{GEREÇ VE YÖNTEM}

\section{Araştırmanın tipi, evren ve örneklem}

Araştırma tanımlayıcı kesitsel araştırma olarak tasarlanmıştır. Araştırmada bir yıl içinde Ege Üniversitesi Tıp Fakültesi Çocuk Hastanesi Yenidoğan ve Genel Pediatri polikliniğine başvuran tüm anneler evreni, Haziran 2017- Haziran 2018 tarihleri arasında araştırmaya katılmaya gönüllü olan 307 anne ise örneklemi oluşturmaktadır.

\section{Araştırmaya dahil edilme kriterleri}

- $\quad$ Okuma yazma bilmesi,

- Türkçe anlayabiliyor ve konuşabiliyor olması,

- Araştırmaya katılmayı kabul etmesidir.

\section{Araştırmaya dahil edilmeme kriterleri}

- $\quad$ Okuma yazma bilmemesi,

- Türkçe anlayamıyor ve konuşamıyor olması

- $\quad$ Araştırmaya katılmayı kabul etmemesidir.

Araştırmada "Birey Tanılama Formu" ve "Emzirme Tutumunu Değerlendirme Ölçeği”" kullanılmıştır.

\section{Veri Toplama Araçları}

Birey Tanılama Formu (Ek-1): Araştırmacılar tarafından literatür bilgileri doğrultusunda hazırlanan, anneye ait sosyo-demografik özellikleri içeren formdur $(3,7,9,11)$.

Emzirme Tutumunu Değerlendirme Ölçeği (ETDÖ) (Ek-2): Emzirme tutumunu değerlendirme ölçeği Özkan tarafından, 1997 yılında İstanbul İlinde 10 hastanenin kadın doğum kliniğinde doğum yapan annelerle çalışılarak geliştirilmiştir. Annelerin emzirme davranışlarını yönlendiren tutumların çeşitli boyutlarının değerlendirilmesi için 5'li likert tipinde 46 maddeden oluşan bir ölçektir. Maddeler tamamen katılıyorum (4), katılıyorum (3), kararsızım (2), az katılıyorum (1), hiç katılmıyorum (0) ifadeleriyle puanlanmıştır. Ölçek olumlu maddeler $(3,4,6,7,8,11,13,15,19,23,24,26,27,28,29,30,31,32,37,38,42,43)$ ve olumsuz maddeler $(1,2,5,9,10,12,14,16,17,18,20,21,22,25,33,34,35,36,39,40$, $41,44,45,46)$ içermektedir. Olumsuz maddeler ters olarak puanlanmıştır. Ölçek toplam puanı 184 dür. Olumlu maddelerin puanı 88, olumsuz maddelerin puanı 96'dır. Puanı yükseldikçe emzirme tutumunun pozitif olduğu yönünde değerlendirilmektedir. Ölçeğin kullanımı için ölçek sahiplerinden gerekli izinler e-posta yolu ile alınmıştır (15).

\section{Etik İlkeler}

Araştırma protokolü ile ilgili Ege Üniversitesi Tıp Fakültesi Tıbbi Araştırmalar Etik Kurulu'ndan etik kurul onayı alınmıştır (04/20 181-2017). Araştırma verilerinin toplanabilmesi için Ege Üniversitesi Tıp Fakültesi Çocuk Hastanesi’nden izin alınmıştır. Araştırmaya dâhil edilen annelere araştırma ile ilgili bilgi verilmiş, çalışmaya katılmaya davet edilmiş, sözlü ve yazılı onamları alınmıştır. 


\section{Araştırma Verilerinin Değerlendirilmesi}

Araştırmadan elde edilen verilerin analizinde SPSS 22.0 paket programı kullanılmıştır. Öncelikle annelerin demografik özelliklerine göre dağılımda frekans ve yüzde dağılımları bakılmış, annelerin emzirme tutumunu değerlendirme puanları frekans, yüzde, aritmetik ortalama ve standart sapma istatistikleri ile değerlendirilmiştir. Verilerin normal dağılıma uygunluğu Kolmogorow-Smirnov testi ile analiz edilmiştir. Ayrıca tüm sosyo-demografik değişkenler seçilerek annelerin emzirme tutumu değerlendime ölçeği puan ortalamasını etkileme durumu istatistiksel olarak One Way Anova testi ve bağımsız gruplarda t testi kullanılarak belirlenmiştir. Etik ilkelere uyulması, araştırma kapsamına alınanların haklarının korunması ve herhangi bir zarar görmemeleri açısından önlemler alınmış, "Emzirme Tutumunu Değerlendirme Ölçeği’nin kullanım izni, ölçek geçerlilik ve güvenirliliğini yapan araştırmacılardan alınmıştır. Araştırmanın uygulanabilmesi için ise Ege Üniversitesi Bilimsel Araştırma ve Yayın Etiği Kurulu'ndan ve araştırmanın yapılacağı kurumdan gerekli yazılı izinler alınmıştır. Araştırmaya kapsamına alınan bireylerden de Yazılı Onam Formu doldurularak izinler alınmıştır.

\section{BULGULAR}

Annelerin sosyo-demografik özellikleri doğrultusunda yaş ortalamasının $28 \pm 6$ olup

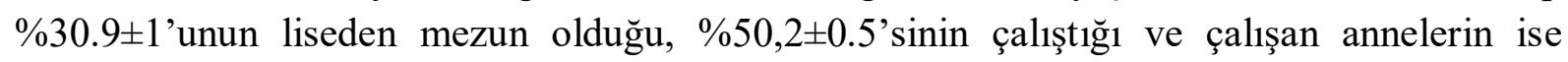
\%23.8'inin memur olduğu saptanmıştır. Çalışmaya katılan ailelerin \%82.1'i çekirdek aile olmakla birlikte ailelerin \%59.9'u il merkezinde yaşamaktadır. Araştırmaya ait sosyodemografik bulgulara Tablo 1'de ayrıntılı olarak yer verilmiştir.

Tablo 1. Annelerin Sosyo-Demografik Özelliklerinin Dağılımı

\begin{tabular}{|c|c|c|c|c|c|}
\hline $\begin{array}{c}\begin{array}{c}\text { Sosyodemografik } \\
\text { Veriler }\end{array} \\
\end{array}$ & Sayı (n) & Yüzde (\%) & $\begin{array}{c}\text { Sosyodemografik } \\
\text { Veriler }\end{array}$ & Sayı (n) & Yüzde (\%) \\
\hline Yaş & & & Aile Tipi & & \\
\hline 15-24 Yaş Arası & 113 & 36.8 & Çekirdek Aile & 252 & 82.1 \\
\hline 25-34 Yaş Arası & 143 & 46.6 & Geniş Aile & 50 & 16.3 \\
\hline 35 Yaş Ve Üzeri & 51 & 16.6 & Parçalanmış Aile & 5 & 1.6 \\
\hline Eğitim & & & Yaşam Alanı & & \\
\hline İlkokul & 49 & 16 & İl Merkezi & 184 & 59.9 \\
\hline Ortaokul & 66 & 21.5 & İlçe & 98 & 31.9 \\
\hline Lise & 95 & 30.9 & Köy & 25 & 8.1 \\
\hline Üniversite & 93 & 30.3 & Eşin Öğrenim Durumu & & \\
\hline Diğer & 4 & 1.3 & İlkokul & 34 & 11.1 \\
\hline Meslek & & & Ortaokul & 32 & 10.5 \\
\hline İşçi & 55 & 17.9 & Lise & 118 & 38.4 \\
\hline Memur & 73 & 23.8 & Üniversite & 120 & 39.1 \\
\hline Esnaf & 9 & 2.9 & Diğer & 3 & 0.9 \\
\hline Ev hanımı & 153 & 49.8 & Eșin Mesleği & & \\
\hline Diğer & 17 & 5.5 & İşçi & 132 & 43 \\
\hline Çalışma Durumu & & & Esnaf & 97 & 31.6 \\
\hline Evet & 154 & 50.2 & Memur & 37 & 12.1 \\
\hline Hayır & 153 & 49.8 & Diğer & 39 & 13.4 \\
\hline
\end{tabular}


Annelerin gebelik sayısına bakıldığında, \%39.7'sinin ilk gebeliği, \%39.4'ünün ise ikinci gebeliği olduğu belirlenmiştir. Annelerin \%83.7'si gebeliğe eşiyle birlikte isteyerek karar verdiklerini belirtmişlerdir ayrıca \%72.3'ünün emzirme deneyiminin olduğu, \%28.8'inin bebeğini 13-18 ay emzirdiği, \%28.4'ünün 19-24 ay emzirdiği belirlenmiştir. Annelerin bebeklerini besleme şekilleri incelendiğinde, \%70'inin emzirdiği, \%7.8'inin beslerken biberon kullandığ 1 , \%2.9'unun nazogastrik sonda ile beslediği, geri kalan annelerin ise bu üç yöntemden herhangi ikisini birlikte kullandığ olup emzirme eğitimi alan annelerin bu eğitimi \%46'sının sağlık personelinden, \%6.8'inin aile büyüklerinden aldıkları saptanmıştır. Annelerin gebelik özellikleri ve emzirme durumlarının dağılımı Tablo 2'de gösterilmiştir.

Çalışmada emzirme tutumu değerlendirme ölçeği toplam puan ortalamasının $85.73 \pm 18$ olduğu saptanmıştır. Ölçekte olumlu maddelerin puan ortalamasının $47.87 \pm 10$, olumsuz maddelerin puan ortalaması ise $37.85 \pm 11$ olduğu belirlenmiştir. Emzirme tutumu değerlendirme ölçeği toplam puan ortalamalarına Tablo 3'de yer verilmiştir.

Tablo 2. Annelerin Gebelik Özellikleri ve Emzirme Durumlarının Dağılımı

\begin{tabular}{|c|c|c|c|c|c|}
\hline Gebelik Özellikleri & Sayı (n) & Yüzde (\%) & $\begin{array}{l}\text { Emzirme } \\
\text { Özellikleri }\end{array}$ & Sayı (n) & Yüzde (\%) \\
\hline \multicolumn{3}{|l|}{ Gebelik Sayısı } & \multicolumn{3}{|c|}{ Emzirme Eğitiminin Nereden Alındığı } \\
\hline 1 & 122 & 39.7 & Sağlık personeli & 138 & 44,6 \\
\hline 2 & 121 & 39.4 & Kitap, gazete, broşür & 15 & 4.7 \\
\hline 3 & 43 & 14. & Aile büyükleri & 29 & 9.2 \\
\hline 4 & 19 & 6.2 & Tv, video, radyo & 8 & 2.5 \\
\hline 5 ve üstü & 2 & 0.7 & Arkadaşlar & 6 & 1.8 \\
\hline \multicolumn{3}{|l|}{ Gebelik İstenme Durumu } & Okuldaki dersler & 7 & 2.2 \\
\hline Eşim ile birlikte istedik & 257 & 83.7 & & & \\
\hline Ben istedim eşim istemedi & 12 & 3.9 & \multicolumn{3}{|c|}{ Emzirirken Yardımcı Araç Kullanma Durumu } \\
\hline \multirow[t]{2}{*}{ Eşim istedi ben istemedim } & 19 & 6.2 & Evet & 232 & 75.6 \\
\hline & 19 & 6.2 & Hayır & 75 & 24.4 \\
\hline Emzirme Özellikleri & Sayı (n) & Yüzde (\%) & \multicolumn{3}{|l|}{ Yardımcı Araç Tipi } \\
\hline \multicolumn{3}{|l|}{ Emzirme Deneyimi } & Silikon meme ucu & 23 & 7.3 \\
\hline Evet & 222 & 72.3 & Süt sağma makinesi & 69 & 22.2 \\
\hline Hayır & 85 & 27.7 & Biberon & 100 & 32.2 \\
\hline \multicolumn{3}{|l|}{ Emzirme Süresi } & Emzirme Örtüsü & 14 & 4.3 \\
\hline $0-6$ ay & 53 & 23.9 & Emzirme Yastığı & 16 & 5 \\
\hline $7-12$ ay & 42 & 18.9 & Göğüs Kalkanı & 1 & 0.3 \\
\hline $13-18$ ay & 64 & 28.8 & Diğer & 2 & 0.6 \\
\hline $19-24$ ay & 63 & 28.4 & & & \\
\hline \multicolumn{6}{|c|}{ Emzirme Eğitimi Alma Durumu } \\
\hline Evet & 232 & 75.6 & & & \\
\hline Hayır & 75 & 24.4 & & & \\
\hline
\end{tabular}

Annelere ait tüm sosyo-demografik özelliklerin ETDÖ puan ortalamasını etkileme durumu incelenmiştir. Yaş, çalışma durumu, meslek, gebelik sayısı, gebeliğin istenme durumu ile emzirme tutumu değerlendirme ölçeği karşılaştırıldığında aralarında anlamlı bir fark olmadığı belirlenmiştir. Eğitim durumu ve emzirme süreleri ile ölçek toplam puanları arasında anlamlı bir fark saptanmıştır $(\mathrm{p}<0.05)$. 
Adnan Menderes Üniversitesi Sağlı Bilimleri Fakültesi Dergisi 2021: 5(1); 84-92

Journal of Adnan Menderes University Health Sciences Faculty

Tablo 3. Emzirme Tutumu Değerlendirme Ölçeği Toplam Puan Ortalamaları

\begin{tabular}{ccccc}
\hline Emzirme Tutum Ölçeği & Min & Max & Ortalama & Std. Sapma \\
\hline Ölçek Toplam Puan & 14 & 122 & 85.73 & 18 \\
Olumlu Madde Puanı & 6 & 78 & 47.87 & 10 \\
Olumsuz Madde Puanı & 8 & 66 & 37.85 & 11 \\
\hline
\end{tabular}

Tablo 4. Emzirme Süresi ile Ölçek Toplam Puanının Karşılaştırılması

\begin{tabular}{|c|c|c|c|c|c|}
\hline Emzirme Süresi & Sayı & & Puan Ort. & \multicolumn{2}{|c|}{ Std. Sapma } \\
\hline $0-6$ ay & 53 & & 84.94 & \multicolumn{2}{|c|}{17} \\
\hline $7-12$ ay & 42 & & 93.14 & \multicolumn{2}{|c|}{14} \\
\hline $13-18$ ay & 64 & & 79.79 & \multicolumn{2}{|c|}{19} \\
\hline $19-24$ ay & 63 & & 85.27 & \multicolumn{2}{|c|}{17} \\
\hline One-Way Anova Testi & Kareler Toplamı & sd & Ortalama Kare & $\mathbf{F}$ & $\mathbf{p}$ \\
\hline Gruplar arası & 4516 & 3 & 1505 & 4.702 & 0.003 \\
\hline Grup içi & 69786 & 218 & 320 & & \\
\hline Toplam & 74302 & 221 & & & \\
\hline
\end{tabular}

\section{TARTIŞMA}

Sağlıklı nesillerin yetişmesi anne ve bebeğin doğum öncesi dönemde sağlık bakım hizmeti almasıyla başlamakta olup bunu doğum sonrası dönemde bu hizmetin devam etmesi takip etmektedir. Doğum sonrası dönemde özellikle annenin yenidoğan ile erken dönem teması, emzirmeye erken başlaması ve annenin emzirmenin sürdürülmesine yönelik tutumu yenidoğanın dış ortama uyum sağlamasını kolaylaştırması ve gelişimini sağlıklı bir şekilde sürdürebilmesi açısından önem taşımaktadır (16). Yaptığımız çalışmada 307 anne çalışma grubuna dahil edilmiş olup annelerin büyük çoğunluğunun (\%46) 25-34 yaş grubunda olduğu belirlenmiştir. Literatürde yaşın emzirme tutumunu etkileyecek önemli bir faktör olduğu belirtilmektedir (9, 17-19). Çalışmamızda ise annelerin yaşları ile emzirme tutum puanları arasında anlamlı bir fark saptanmamıştır. Literatürde yaşın emzirme tutumunu etkileyebilecek bir faktör olması ile ilgili farklı bulgular mevcuttur. Koç ve Tezcan'ın çalışmasında ise anne yaşı arttıkça emzirme tutum puan ortalamasının yükseldiği, Kurnaz'ın çalışmasında ise tam tersi yaş arttıkça emzirme tutum puan ortalamasının azaldığ 1 belirlenmiştir $(17,18)$.

Yapılan çalışmanın analizinde annelerin eğitim düzeyi ile emzirme tutumu arasında anlamlı bir fark olduğu, ilkokul mezunu olan annelerin emzirme tutum puanının daha yüksek olduğu saptanmıştır (F: 2.86, p: 0,024). Eğitim düzeyi arttıkça annelerin emzirme tutum puanının düştüğü belirlenmiştir. Bu durumun üniversite mezunu olan annelerin çalışma durumu ve emzirme süresindeki kesintiden kaynaklanabileceği düşünülmektedir. Koç ve Tezcan'ın (2005) çalışmasında annelerin eğitim düzeyi ile emzirme tutum puanı arasında anlamlı fark olmamasına rağmen, eğitim düzeyi arttıkça annelerin emzirme tutum puanının arttığ belirlenmiştir, benzer şekilde Kurnaz'ın (2014) çalışmasında da eğitim düzeyi arttıkça annelerin emzirme tutum puanı artmaktadır $(17,18)$. Literatürde eğitim düzeyi ile emzirme bilgi ve tutumu arasında ilişkiye yönelik farklı sonuçları olan çalışmalar bulunmaktadır (17-21). Araştırmada annelerin gebelik sayısı ile emzirme tutum puanı arasında anlamlı bir ilişki olmamasına rağmen literatürün aksine gebelik sayısı arttıkça annelerin emzirme tutum puanının 
arttığ1 görülmektedir. $(9,18)$. Bunun nedenin annelerin ilk gebeliklerinde tecrübesiz olup daha sonraki gebeliklerinde emzirmenin önemini kavramaları ve bu konuda eğitim almaları olabilir. Ülkemizde emzirme ile ilgili bilgi annelere sıklıkla doğumdan sonra, hastanede kaldığ 1 süre içinde verilmektedir (22). Anne doğum nedeniyle hastaneye daha sık başvurduğunda emzirme ile ilgili yeni bilgiler öğrenme ve bilgilerini yenileme firsatı da daha çok olacağ düşünülmektedir.

Çalışmada Yiğitbaş ve ark. (2012) çalışmasına benzer şekilde emzirme deneyimi ile emzirme tutum puanı arasında anlamlı bir fark saptanmamıştır. Emzirme eğitimi alma durumu ile emzirme tutumu arasında anlamlı bir fark saptanmış olup emzirme eğitimi alan grubun emzirme tutum puan ortalaması daha düşük olduğu belirlenmiştir $(\mathrm{t}=2.4 \mathrm{p}=0.017)$. Kurnaz'in (2014) çalışmasında ise emzirme eğitimi alan annelerin emzirme tutum puan ortalamasının daha yüksek olduğu saptanmıştır (18). Çalışmada emzirme süresi ile emzirme tutum puanı arasında anlamlı bir fark saptanmıştır. Bebeğini 7-12 ay emziren annelerin emzirme tutum puan

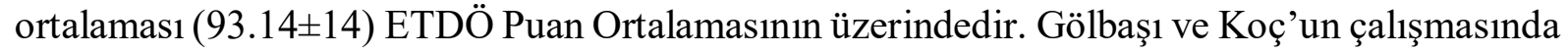
ise emzirme süresi ile emzirme tutum puanı arasında anlamlı bir fark saptanmamıştır. Ancak emzire tutum puan ortalamaları bizim çalışmamızdan yüksek bulunmuştur (23).

ETDÖ’den alınabilecek en yüksek puan 184, ölçek puan ortalaması ise 90'dır. Ölçekten alınan puan arttıkça annelerin emzirmeye ilişkin tutumları olumlu olarak değerlendirilmektedir. Yiğitbaş ve Kahriman'ın çalışmasında annelerin emzirme tutumu puan ortalamas $16.34 \pm 18.81$, Tuzcu ve Zencir'in çalışmasında ise $85.82 \pm 23.21$ bulunmuştur $(9,24)$. Çalışma sonuçları yapılan çalışma sonuçlarıyla benzerlik göstermektedir. Gölbaşı ve Koç'un (2008) çalışmasında

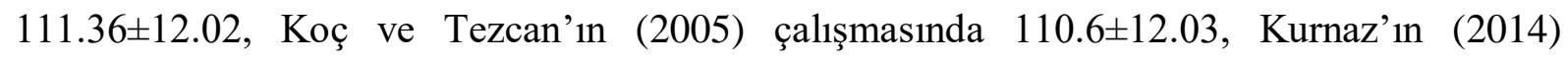

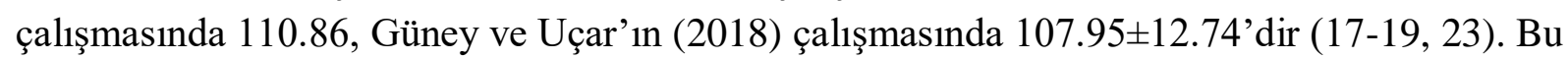
sonuçlar ise yapılan çalışma sonuçlarından daha yüksek olmakla birlikte annelerin emzirme tutumlarının daha olumlu olduğunu göstermektedir.

\section{SONUÇ}

Çalışma sonuçlarına göre annelerin emzirme tutumu puan ortalaması ETDÖ puan ortalamasının çok altındadır. $\mathrm{Bu}$ durumun örneklem grubunun az olmasından kaynaklanabileceği gibi emzirmeyi etkileyecek diğer biyolojik, psikolojik, sosyal, kültürel ve ekonomik etkenlerden etkilenebileceği düşünülmektedir.

Annelerin ve anne adaylarının doğum öncesinden başlanarak emzirme davranış ve tutumlarının geliştirilmesi için gerekli eğitimler düzenlenmelidir. Emzirmenin teşvik ve geliştirilmesinde antenatal eğitimlerin özellikle doğuma hazırlık sınıfları ve gebe okulları büyük katkı sağlayacaktır. Doğum sonu ilk andan başlayarak servis hizmetleri sırasında ebe ve emzirme hemşirelerinin gerekli eğitimi almak koşuluyla, emzirmenin önemine olan inançla verecekleri eğitimin, emzirme desteğinin hem anne hem de bebek yaşamında önemli role sahiptir. Anneler, sağlık politikaları doğrultusunda kamu spotu, sosyal medya aracılığıyla emzirmeye teşvik edilmeli ve emzirmeyi destekleyici uygulamalar hayata geçirilmelidir. Emzirmenin anne bebek sağlı̆̆ına etkileri konusunda örgün eğitimde ilgili derslerde ebelik ve hemşirelik öğrencilerinin bilgi ve becerileri arttırılmalı, buna yönelik uygulamalar konusunda öğrenciler bilinçlendirilmelidir. Lisansüstü düzeyinde ise emzirme danışmalığı sertifikası almaları sağlanarak, bu doğrultuda danışmanlık hizmetleri arttırılmalıdır. 


\section{Araştırmanın Etik Yönü}

Araştırma protokolü ile ilgili Ege Üniversitesi Tıp Fakültesi Tıbbi Araştırmalar Etik Kurulu'ndan etik kurul onayı alınmıştır (04/20 181-2017). Araştırma verilerinin toplanabilmesi için Ege Üniversitesi Tıp Fakültesi Çocuk Hastanesi'nden izin alınmıştır. Araştırmaya dâhil edilen annelere araştırma ile ilgili bilgi verilmiş, çalışmaya katılmaya davet edilmiş, sözlü ve yazılı onamları alınmıştır.

\section{Çıkar Çatışması}

Yazarlar arasında çıkar çatışması yoktur.

\section{KAYNAKLAR}

1. Alb, CH., Theall, K., Jacobs, MB., Bales, A. (2016). Awareness of United States' law for nursing mothers among employers in New Orleans, Louisiana. Women's Heal Issues. Jacobs Institute of Women's Health, 27(1), 14-20.

2. American Academy Of Pediatrics Policy. (2005). Breastfeeding and the use of human milk. Pediatrics, 115(2), 496-506.

3. Darwent, KL., McInnes, RJ., Swanson, V. (2016). The Infant feeding genogram: a tool for exploring family infant feeding history and identifying support needs. BMC Pregnancy Childbirth, 16(1), 315.

4. Anatolitou, F. (2012) Human milk benefits and breastfeeding. Journal of Pediatric and Neonatal Individualized Medicine, 1(1),11-18.

5. Alp, H., Altınkaynak, S., Yıldız, L. (1991). Anne sütünün enfeksiyonlardan koruyucu etkisi. Aile ve Toplum, 1(1).

6. Kramer, M.S., Kakuma, R. (2006). Optimal duration of exclusive breastfeeding. Reproduction And Contraceptıon-Shanghal-Instıtute Of Planned Parenthood Research, 26(4), 237.

7. Chaput, KH., Adair, CE., Nettel-Aguirre, A., Musto, R Tough. (2005). The experience of nursing women with breastfeeding support: A qualitative inquiry. C Open, 3(3), 305309.

8. Park, MJ., Adams, SH., Irwin, CE. (2011) Health care services and the transition to young adulthood: Challenges and opportunities. Acad Pediatr, 11(2), 115-22.

9. Yiğitbaş, Ç., Kahriman, İ., Çalık, KU., Bulut HB. (2012) Trabzon İl Merkezindeki Hastanelerde Doğum Yapan Annelerin Emzirme Tutumlarinin değerlendirilmesi. Gümüşhane Üniversitesi Sağlık Bilim Dergisi, 1(2), 49-59.

10. Conk, Z., Başbakkal, Z., Yılmaz, H.B., Bolışık B. (2018) Pediatri Hemşireliği. Ankara, Akademisyen Tip Kitapevi.

11. Depresyon, P. (2016) Postpartum depresyonun emzirme üzerine etkisi the effects of postpartum depression on breastfeeding. Gümüşhane Üniversitesi Săgllk Bilimleri Dergisi, 5(3), 90-6.

12. Selimoğlu, MA. (2013) Anne ve bebek sağlığı açısından emziren anne beslenmesinin önemi. Türk Pediatri Arşivi, 183-7.

13. Türkiye Nüfus ve Sağlık Araştırması Raporu, 2018.

14. Kayhan, TB. (2016) Anne sütü ve emzirme danışmanlığında güncel bilgiler. Med J, 16(1):115-8.

15. Özkan, HA. (2015) Emzirme tutumunu değerlendirme ölçeği. KASHED, 2(1):53-8.

16. Aydın, D., Aba, YA. (2019) Annelerin sağlık okuryazarlığı düzeyleri ile emzirme 
özyeterlilik algıları arasındaki ilişki. DEUHFED, 12(1), 31-39.

17. Koç GI., Tezcan S. (2005) Gebelerin emzirmeye ilişkin tutumları ve emzirme tutumunu etkileyen bazı faktörler. Hacettepe Üniversitesi Hemşirelik Yüksekokulu Dergisi, 12(1), $1-13$.

18. Kurnaz, D. (2014). Erken postpartum dönemde annelerin emzirmeye ilişkin tutum ve başarılarını etkileyen faktörler. "Yayınlanmamış Yükseklisans Tezi". Adnan Menderes Üniversitesi Sağlık Bilimler Enstitüsü Ebelik Anabilim Dalı, Aydın.

19. Güney, E., Uçar, T. (2018). Gebelikteki beden imajının emzirme tutumu ve doğum sonu emzirme sürecine etkisi. Zeynep Kamil Tip Bülteni, 49(1), 49-53.

20. Ünsal, H., Atlıhan, F., Özkan, H., Targan, Ş., Hassoy, H. (2005) Toplumda anne sütü verme ve buna etki eden faktörler. Çocuk Sağlığı ve Hastalıkları Dergisi, 48, 226-233.

21. Şahin, G. (2008) Emziren annelerin emzirme ile ilgili bilgi, uygulama ve davranışlarının değerlendirilmesi. "Uzmanlık Tezi". T.C. Sağlık Bakanlığı İstanbul Göztepe Eğitim Ve Araştırma Hastanesi Aile Hekimliği Koordinatörlüğü, İstanbul.

22. Yılmaz, C., Taşpınar A. (2017) Doğum sonrası erken dönemde ebeveynlere verilen emzirme eğitiminin bebeklerin ilk altı ay anne sütü alma durumuna etkisi. Gümüşhane Üniversitesi Sağllk Bilimleri Dergisi, 6(3), 25-34.

23. Gölbaşı, Z., Koç, G. (2008) Kadınların postpartum ilk 6 aylık süredeki emzirme davranışları ve prenatal dönemdeki emzirme tutumunun emzirme davranışları üzerindeki etkisi. Să̆lık Bilimleri Fakültesi Hemşirelik Dergisi, 16-31.

24. Tuzcu, A., Zencir, M. (2000) Denizli il merkezi yataklı tedavi kurumlarında doğum yapan annelerin emzirme tutumlarının değerlendirilmesi. Ege Üniversitesi Hemşirelik Yüksek Okulu Dergisi, 16(1), 47-56. 